\title{
MODELLING OF THE 3D MACHINING GEOMETRIC DEFECTS ACCOUNTING FOR WORKPIECE VIBRATORY BEHAVIOUR
}

\author{
Chaari, R.; Abdennadher, M.; Louati, J. \& Haddar, M. \\ Mechanics Modelling and Production Research Unit (U2MP), Mechanical Engineering Department, \\ University of Sfax, National Engineering School of Sfax (E.N.I.S.), B.P 3038 - Sfax, Tunisia \\ E-Mail: rchaari@yahoo.fr
}

\begin{abstract}
In this paper, we present a three-dimensional manufacturing tolerancement model. Several researchers have interested to modelling the machining geometric defects. The most researchers are limited to kinematic and static study. Only some works are evoked the dynamic effects, especially the influence of the chatter phenomenon on the roughness of the machined surface. In this context, the paper presents a contribution for modelling and quantification of the machining geometric defects where the machining dynamic effects are considered. A developed method is established based on Homogeneous Transformation Method in subject to determine the kinematical deviations caused by part locating and relocating. The dynamic displacements due to clamping and machining forces are defined using Finite Element Method. The numerical results are then compared to published experimental results.

(Received in July 2010, accepted in February 2011. This paper was with the authors 2 months for 1 revision.)
\end{abstract}

Key Words: Machining, Defects, Tolerancing, Dynamic

\section{INTRODUCTION}

The fixturing and resultant quality study have two principal topics: 1) the analysis of fixture errors under different conditions, such as the rigid body assumption, the deformable workpiece, or the dynamic errors; 2) the design and optimization of fixtures.

In fixture analysis, Shawki and Abdel-Aal [1] presents an experiment study of the influence of fixture rigidity and wear condition on dimensional accuracy. Basing on the worst-case assumption and rigid-body errors, Salisbury and Peters [2] study the impact of workpiece surface error on the workpiece location and orientation. Chaari R. et al. [3] studies the influence of the fixture errors on the respect of the orientation geometric specifications. De Meter [4] presented a linear model for predicting the effect of locator and clamp placement on workpiece displacement. Hockenberger and De Meter [5] studied the impact of fixture design parameters, such as the fixture layout, locator contact region geometry, and clamping intensity, on the workpiece displacement. The finite element method is used by Menassa and DeVries [6] to optimize the fixture locator positions by minimizing the workpiece deflection.

However, the fixture-workpiece system is modelled in most works by a quasi-static model; the dynamic behaviour is not considered. For example, DeMeter et al. [7] considered a static deformation for both clamping and machining. They have developed a linear programming (LP) model to compute the minimum required clamp pre-loads to prevent workpiece slip at the fixture-workpiece contacts during machining. Liu and Melkote [8] modelled the change of the workpiece gravity during machining. Kaya and Ozturk [9] applied an FE-based element death technique to simulate the chip removal process for fixture layout verification. However, both papers treat the fixture-workpiece system as quasi-static. 
Some researchers have interested to the dynamic behaviour of the fixture-workpiece system. Liao and $\mathrm{Hu}$ [10] integrated a FEA model to predict the machined surface quality under the influence of clamping forces and vibrations of the fixture-workpiece system. Mittal et al. [11] modelled a fixture-workpiece system using the Dynamic Analysis and Design System (DADS) software and modelled the fixture-workpiece contact as a lumped springdamper-actuator element. Liao and Hu [12] extended Mittal et al.'s work by including the workpiece compliance effect and contact friction through combined use of the finite element (FE) method and DADS.

Few numbers of researchers modelled the machining geometric defects by considering the machining dynamic effects. In this paper a tensorial model is proposed to quantify the machining geometric defects. In this model, the vibratory behaviour of workpiece during the machining is considered.

This paper presents a new model and procedure to quantify the machining geometric defects. Unlike previous work, the machining dynamic effects and dynamic workpiece behaviour are considered. The kinematical deviation due to part locating and relocating is modelled by the Homogeneous Transformation Method. The finite element method is used to establish the dynamic displacements caused by clamping and machining forces.

\section{PROBLEM FORMULATION AND APPROACH}

The milling of a workpiece is characterized by periodic cutting forces. When the excitation frequency is near to the resonance, the dynamic behaviour of workpiece is critical, especially for the flexible workpiece. For this reason, it is important to consider the machining dynamic effect in order to quantify the geometric defects and to verify the respect of geometrical specifications. In the literature, several previous research works treated the modelling of the influence of the dynamic behaviour of the workpiece on the quality of machining. Indeed, the majority of these research works modelled and quantified the influence of the machining dynamic effects and especially the influence of the chatter phenomenon on the roughness of the machined surface of a rigid or flexible workpiece. Then the objective of this paper is to analyze the influence of the fixture errors and the machining dynamic effects on the respect of geometrical specifications. Indeed a procedure is developed in order to model and quantify the generated geometric defects during the machining. This procedure is based on a tensorial approach.

The developed procedure is presented in Fig. 1. It's consists to develop:

- A geometry model of the machined surface. It's described by a homogeneous matrix which founds the coordinates of $N$ surface points. The model is based on the principle of threedimensional measurement machines (MMT).

- A tensorial model to describe the fixture errors caused by small displacements of a rigid body.

- A tensorial model to describe the clamping errors caused by small rigid body displacements and on the other hand clamping errors caused by the elastic strain.

- A dynamic model to quantify dynamic displacements of the machined surface with each tool displacement and to update the tensor which describes machined surface. The regenerative dynamic displacements effects on the tool-workpiece interaction are considered in this model.

- A quantification tensorial model of geometrical defects. This model verifies the respect of the geometric specifications, using algorithms based on the linear least squares estimation method. 


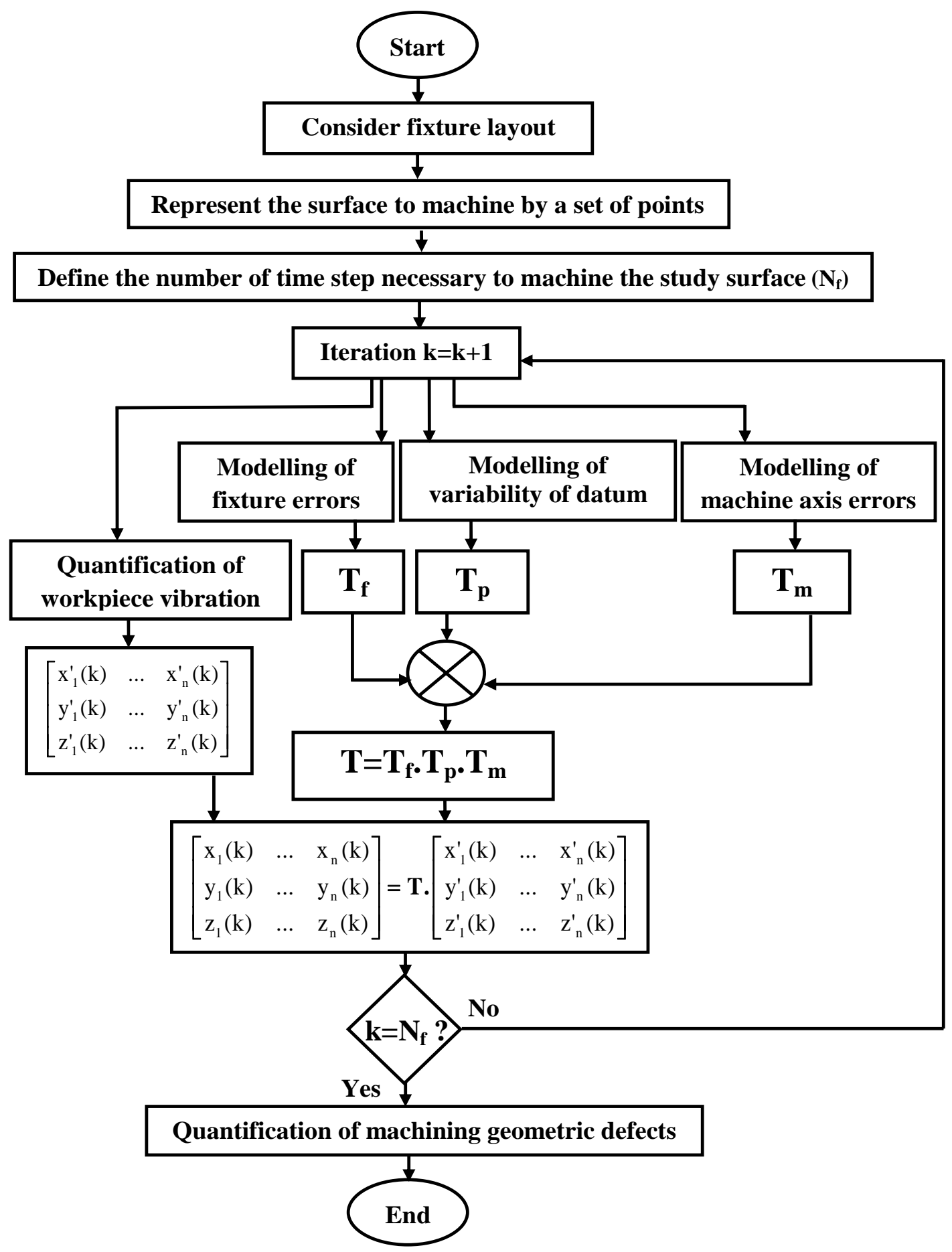

Figure 1: Modelling and quantification procedure of machining geometric defects.

This developed procedure presented by Fig. 1 is based on the following assumptions:

- The Hertzian model holds for all contacts.

- Coulomb friction is present at all contacts.

- The coupling between the vibration of the tool and the workpiece is done by the cutting force in a node.

- The materials of workpiece, the fixtures and the clamps are considered perfectly elastic and isotropic.

- All deformations are linearly elastic and small.

- The thermal error effects are considered negligible. 


\subsection{Workpiece representation}

The workpiece is represented by a set of surface points. Theses points (Fig. 2) are extracted from the mesh model generated from the FEA software. Then, the coordinates points are represented by a homogeneous matrix noted $\mathrm{X}_{0}$. These coordinates are organized into $4 * m$ (where $m$ is the number of points).

$$
X_{0}=\left[\begin{array}{llll}
p_{1} & p_{2} & \cdots \cdots & p_{m}
\end{array}\right]_{0}=\left[\begin{array}{ccc}
x_{1} & \ldots & x_{m} \\
y_{1} & \ldots & y_{m} \\
z_{1} & \ldots & z_{m} \\
1 & 1 & 1
\end{array}\right]_{0}
$$
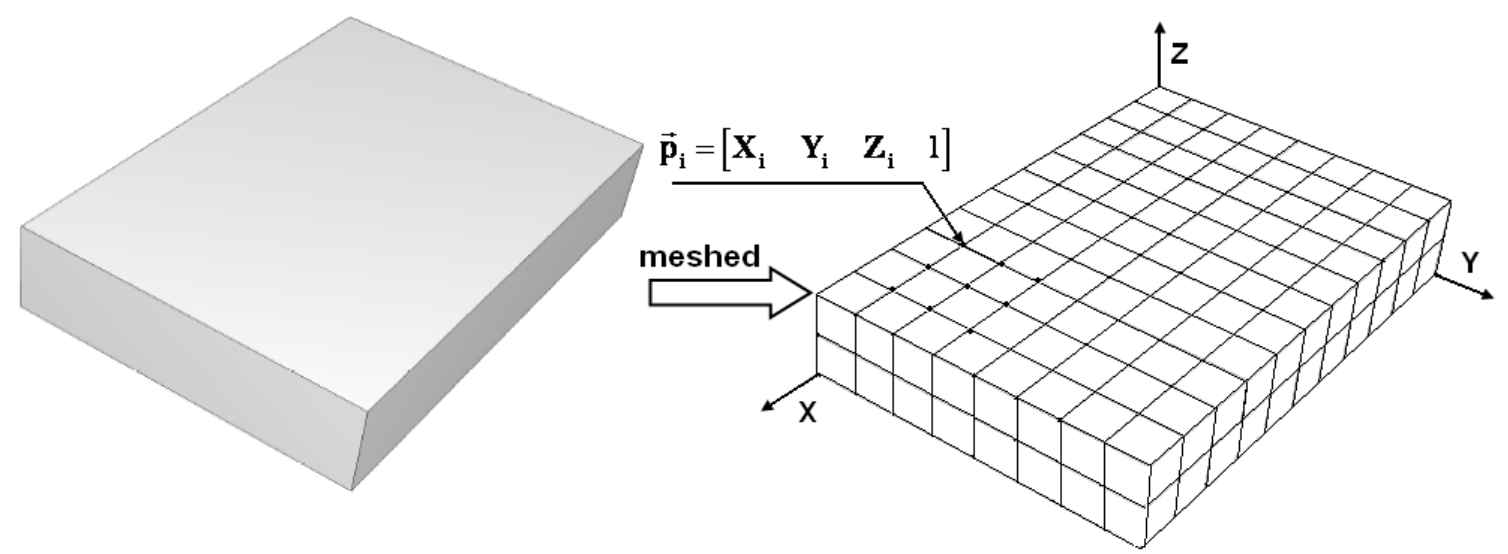

Figure 2: Representation of the workpiece.

Where $p_{i}=\left[\begin{array}{llll}x_{i} & y_{i} & z_{i} & 1\end{array}\right]^{\prime} \quad(i=1$ to $m$ ) represents the homogeneous coordinates of a point $p_{i}$ on the workpiece.

\subsection{Modelling of the homogeneous matrix $T_{f}$}

The homogeneous matrix of the geometric transformations generated by the fixture errors is proven as [14]:

$$
T_{f}=\left[\begin{array}{cccc}
1 & \delta \theta_{z f} & -\delta \theta_{y f} & \delta x_{f} \\
-\delta \theta_{z f} & 1 & \delta \theta_{x f} & \delta y_{f} \\
\delta \theta_{y f} & -\delta \theta_{x f} & 1 & \delta z_{f} \\
0 & 0 & 0 & 1
\end{array}\right]
$$

The fixture errors can be generated using the Monte Carlo simulation given the tolerance of the fixture.

\subsection{Modelling of the homogeneous matrix $T_{p}$}

The homogeneous matrix of the geometric transformations generated by variability of the datum surface is proven by the Monte Carlo method [14]:

$$
T_{p}=\left[\begin{array}{cccc}
1 & \delta \theta_{z p} & -\delta \theta_{y p} & \delta x_{p} \\
-\delta \theta_{z p} & 1 & \delta \theta_{x p} & \delta y_{p} \\
\delta \theta_{y p} & -\delta \theta_{x p} & 1 & \delta z_{p} \\
0 & 0 & 0 & 1
\end{array}\right]
$$




\subsection{Modelling of the homogeneous matrix $T_{m}$}

The machine errors are represented by HTMs according to the machine specifications or calibration. In general, the axial linear/angular accuracy of a machine is specified as the mean shift $( \pm \Delta \mu)$ of a parameter while the repeatability is specified with the varying range $( \pm 3 \sigma)$ with respect to its mean value. For example, the HTM of x-axis on a machine can be expressed as [14]:

$$
T_{x m}=\left[\begin{array}{cccc}
1 & -\delta \theta_{z m} & -\delta \theta_{y m} & \delta x_{m} \\
\delta \theta_{z m} & 1 & \delta \theta_{x m} & \delta y_{m} \\
\delta \theta_{y m} & -\delta \theta_{x m} & 1 & \delta z_{m} \\
0 & 0 & 0 & 1
\end{array}\right]
$$

where $\delta x_{m}=N\left(\Delta \mu_{x m}, \sigma_{x m}^{2}\right)$ and other parameters are determined in a similar way. For a machining operation on a 3-axis machine, the machine error is reflected onto the workpiece by the following expression:

$$
\vec{p}=\left(T_{m}\right)^{-1} \vec{p}^{\prime}=\left(T_{x m} \cdot T_{y m} \cdot T_{z m}\right)^{-1} \cdot \vec{p}^{\prime}
$$

\subsection{Modelling of the dynamic effects}

The dynamic equations of the workpiece are established using a FEM method. The workpiece is discretized by a parallelepiped finite element defined by eight nodes and three degrees of freedom per node. The dynamic equation is then obtained using Lagrange formulation [16]:

$$
\left[M_{w}\right] \ddot{q}_{w N}+\left[C_{w}\right] \dot{q}_{w N}+\left[K_{w}\right] q_{w N}=Q_{c / w}(t)
$$

where $M_{w}$ is the workpiece mass matrix, $K_{w}$ is the workpiece rigidity matrix, $C_{w}$ is the damping matrix defined using Rayleigh viscous equivalent damping model, $q_{w N}=\left[\begin{array}{lll}X & Y & Z\end{array}\right] \in R^{3}$ is the workpiece nodal motion vector and $Q_{c / w}(t)=\left(F_{X_{c / w}}(t), F_{Y_{c / w}}(t), F_{Z_{c / w}}(t)\right) \in R^{3}$ is the vector of the cutting tool action on the workpiece caused by external cutting loads.

The spindle model is restricted to the rotating entity. An experimental modal identification procedure was carried out on the different spindle entities [17] and showed that spindle behaviour can be restricted to rotating entity behaviour. The motion of the rotating entity is considered as the superposition of rigid and elastic body displacements. Dynamic equations are obtained using Lagrange formulation associated with a finite element method. Then the rotating entity is derived using Timoshenko beam theory. A special 3D rotor beam element with two nodes and six degrees of freedom per node is used. The spindle damping model used draws on Rayleigh viscous equivalent damping, which makes it possible to regard the damping matrix $C_{c}$ as a linear combination of the spindle mass matrix $M_{c}$, the spindle rigidity matrix $K_{c}$. The set of differential equations can be written as:

$$
\left[M_{c}\right] \ddot{q}_{c N}+\left[C_{c}\right] \dot{q}_{c N}+\left[K_{c}\right] q_{c N}=Q_{W / c}(t)
$$

where, $\quad q_{c N}=\left[\begin{array}{lll}X & Y & Z\end{array}\right] \in R^{3} \quad$ is the spindle nodal motion vector and $Q_{w / c}(t)=\left(F_{X_{w} / c}(t), F_{Y_{w / c}}(t), F_{Z_{w / c}}(t)\right) \in R^{3}$ is the vector of the cutting workpiece reaction on the cutting tool caused by external cutting loads.

The dynamic displacement of each point of the machined surface is then obtained using a quantification procedure (Fig. 3). In this procedure the regenerative dynamic effects at the 
workpiece-tool interaction and the static displacements caused by the clamping forces is considered.

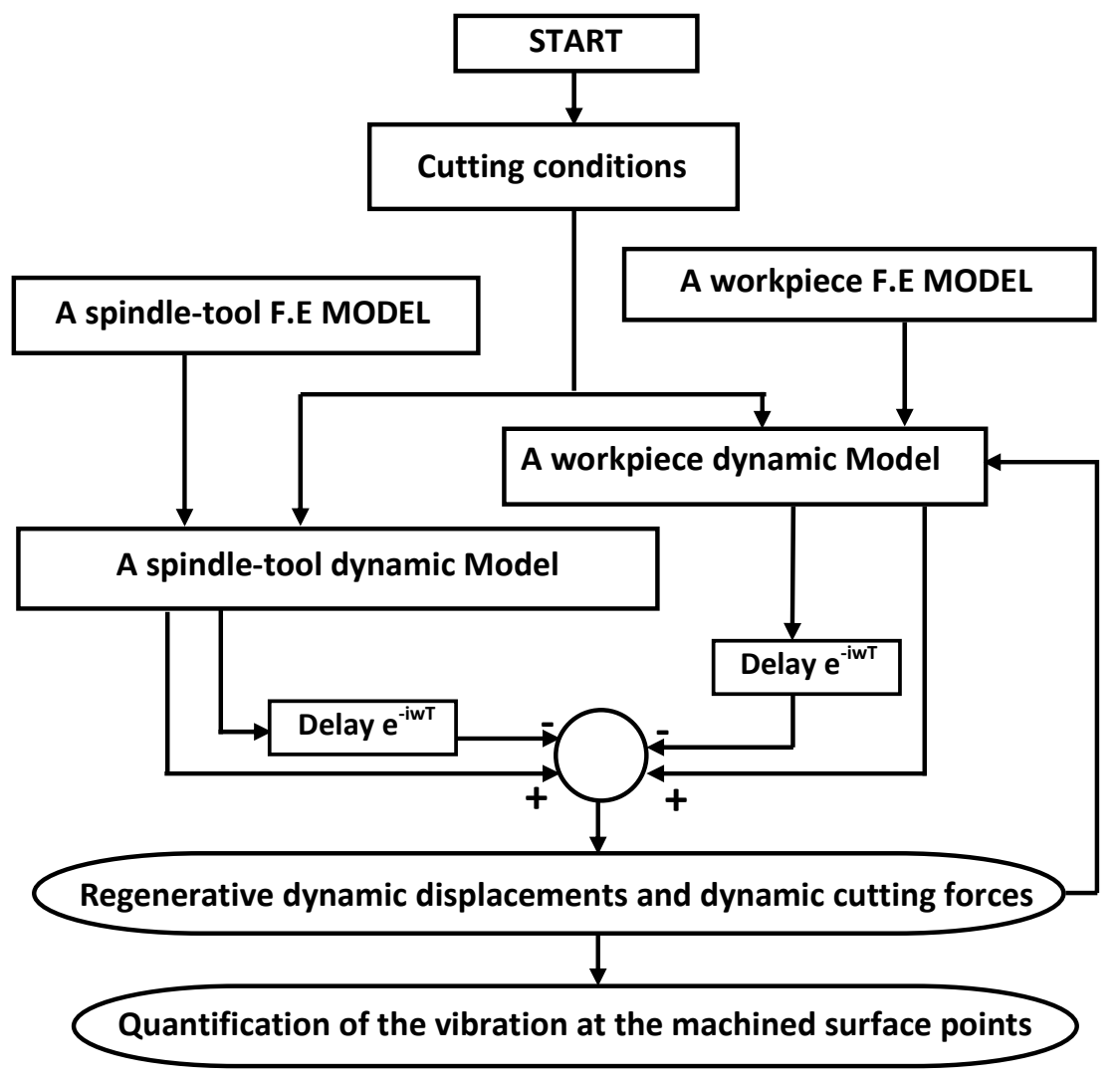

Figure 3: Procedure of the quantification of the vibration at the machined surface points.

A machined surface is represented by a set of points. Based on this procedure presented by Fig. 3, the coordinates of the machined surface points are calculated at each time step. Then the matrix presented by Eq. (8) founds the new instantaneous coordinates of the machined surface. This matrix will be updated at each $i^{\text {th }}$ machined time step:

$$
X(i)=\left[\begin{array}{ccc}
\mathrm{x}_{1}(\mathrm{i}) & \ldots & \mathrm{x}_{\mathrm{n}}(\mathrm{i}) \\
\mathrm{y}_{1}(\mathrm{i}) & \ldots & \mathrm{y}_{\mathrm{n}}(\mathrm{i}) \\
\mathrm{z}_{1}(\mathrm{i}) & \ldots & \mathrm{z}_{\mathrm{n}}(\mathrm{i})
\end{array}\right]
$$

where $n$ is the number of machined surface points.

\subsection{Variation superposition}

Variation from different variation sources can be superposed under the small error assumption. For kinematic variations, the superposition is accomplished by multiplying the HTMs of each component. Dynamic displacements of the machined surface are presented at each time step by the matrix that founds the representative points' coordinates of the machined surface. Then the new surface generated on the workpiece at $i^{\text {th }}$ time step is represented as:

$$
\left[\begin{array}{ccc}
\mathrm{x}_{1}(\mathrm{i}) & \ldots & \mathrm{x}_{\mathrm{n}}(\mathrm{i}) \\
\mathrm{y}_{1}(\mathrm{i}) & \ldots & \mathrm{y}_{\mathrm{n}}(\mathrm{i}) \\
\mathrm{z}_{1}(\mathrm{i}) & \ldots & \mathrm{z}_{\mathrm{n}}(\mathrm{i})
\end{array}\right]=T_{f} \cdot T_{p} \cdot T_{m}\left[\begin{array}{ccc}
\mathrm{x}_{1}^{\prime}(\mathrm{i}) & \ldots & \mathrm{x}_{\mathrm{n}}^{\prime}(\mathrm{i}) \\
\mathrm{y}_{1}^{\prime}(\mathrm{i}) & \ldots & \mathrm{y}_{\mathrm{n}}^{\prime}(\mathrm{i}) \\
\mathrm{z}_{1}^{\prime}(\mathrm{i}) & \ldots & \mathrm{z}_{\mathrm{n}}^{\prime}(\mathrm{i})
\end{array}\right] \text { for } i=1 \text { to } n
$$




\section{QUANTIFICATION OF THE GEOMETRIC DEFECTS}

In this section we present two quantification algorithms of the geometric defects that influenced the respect of the geometric conditions of parallelism and flatness. These algorithms based on the linear least squares estimation method (LLSE) and some geometric interpretations of the presented geometric conditions.

\subsection{Geometric condition of parallelism}

The parallelism refers to the minimum distance between two parallel planes (or lines) that enclose a set of measurement points such that the two planes (or lines) are parallel to a reference plane (or line). The parallelism property for planes can be illustrated in the following Fig. 4.

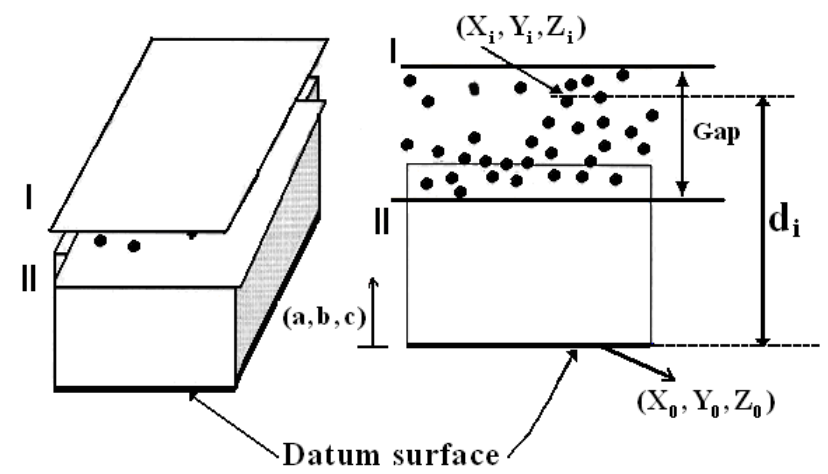

Figure 4: Interpretation of geometric defects that influences the parallelism [15].

Assuming that a point is represented as $\left(x_{i}, y_{i}, z_{i}\right)$ and the plane is represented as $\left(x_{0}, y_{0}, z_{0}\right)$ and $(a, b, c)$, the deviation from this point to the plane is:

$$
d_{i}=a\left(x_{i}-x_{0}\right)+b\left(y_{i}-y_{0}\right)+c\left(z_{i}-z_{0}\right) ; i=1 \text { to } n
$$

For a set of $n$ points, the gap (or distance) between two parallel planes is:

$$
\text { Gap }=\max \left(d_{i}\right)-\min \left(d_{i}\right) ; i=1 \text { to } n
$$

This gap presents the geometric defects which influence the condition of the parallelism.

\subsection{Geometric condition of flatness}

The flatness is defined as the minimum distance between two parallel planes (parallel to the least square fit plane) that covers the measured surface. Assuming that a point is represented as $\left(x_{i}, y_{i}, z_{i}\right)$ and the fitting plane is represented as $\left(\widehat{x}_{0}, \hat{y}_{0}, \widehat{z}_{0}\right)$ (a point of the fitting plane) and the normal vector $(\hat{a}, \widehat{b}, \widehat{c})$, the deviation from this point to the plane is:

$$
d_{i}=\widehat{a}\left(x_{i}-\widehat{x}_{0}\right)+\widehat{b}\left(y_{i}-\widehat{y}_{0}\right)+\widehat{c}\left(z_{i}-\widehat{z}_{0}\right) ; i=1 \text { to } n
$$

For a set of $n$ points, the distance between two parallel planes is:

$$
\text { dist }=\max \left(d_{i}\right)-\min \left(d_{i}\right) ; i=1 \text { to } n
$$

The deviation (dist) has to be smaller than the tolerance specification for the flatness.

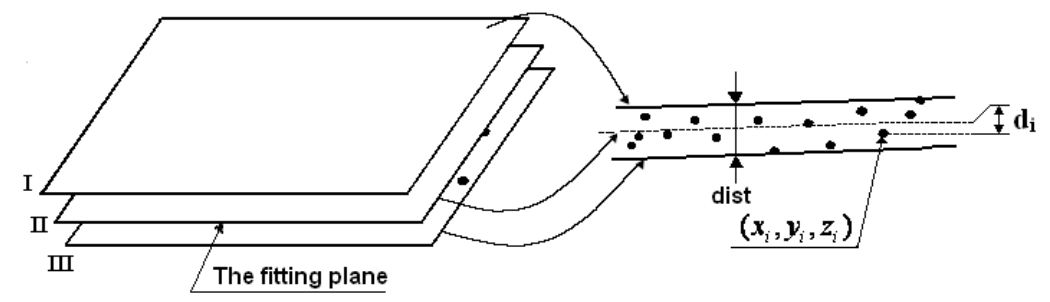

Figure 5: Interpretation of geometric defects that influences the flatness [15]. 


\section{NUMERICAL SIMULATION}

A numerical simulation for the developed model is conducted with the assumptions that thermal error effects are negligible. An end milling operation is conducted on the top surface of a hat shaped workpiece with 3-axis vertical machining center. The cutting tool has 6 triangles, CVD coated inserts with $0^{\circ}$ lead angle, $30^{\circ}$ face cutting edge angle, $1^{\circ}$ radial rake angle and $5^{\circ}$ axial rake angle. The material of the workpiece is aluminium Al-7085 and the dimensions are shown in Fig. 6.

We treated in this numerical application, the same example treated by Weiping Zhong [13-14] in order to compare our numerical results with the Weiping experimental results. In [14], Weiping quantified numerically and experimentally only the geometric defects that influence the flatness of the machined surface.

In order to validate our model, we compare our numerical simulation of the flatness with a Weiping experimental result [14]. Then in our simulation, we quantified the geometric defects that influence the flatness and the parallelism of the machined surface.
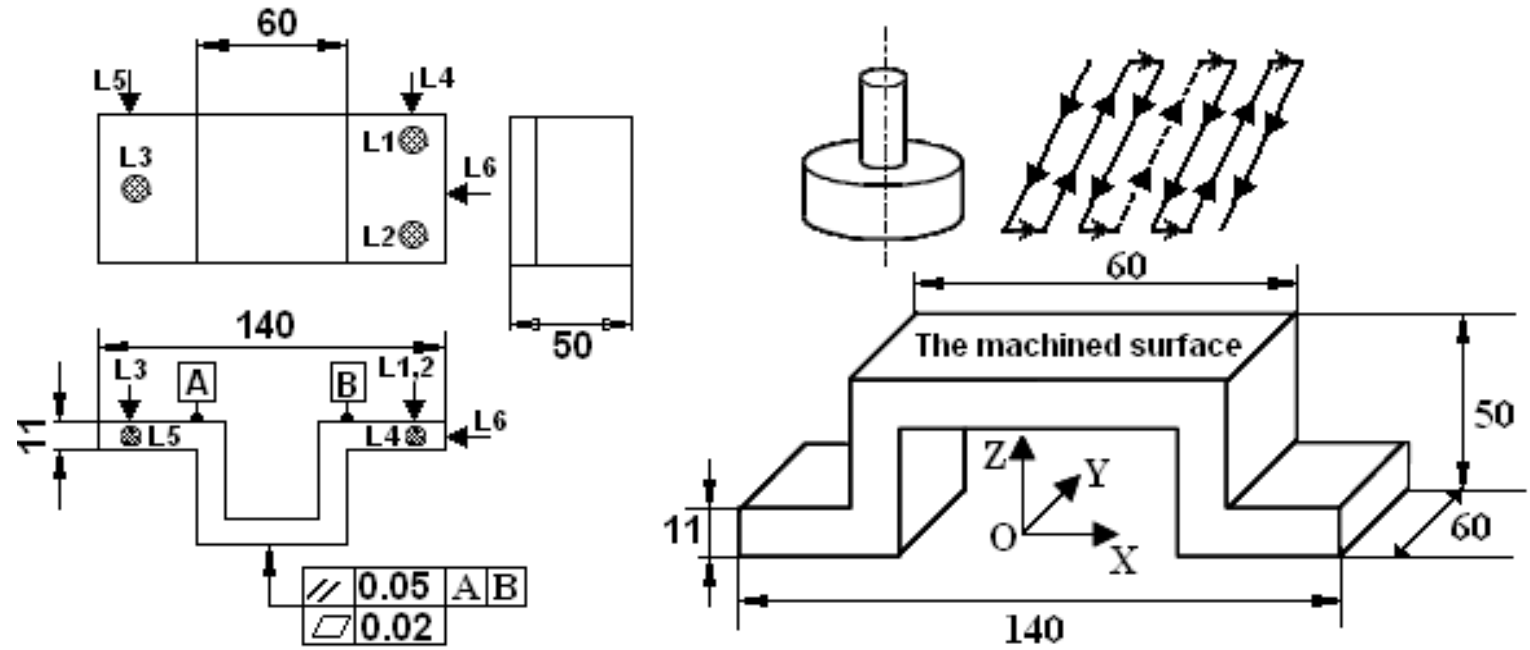

Figure 6: Presentation of the simulated example [14].

The fixturing of the workpiece is ensured by a 3-2-1 fixture layout. The coordinates of contact points between the workpiece and the fixtures are presented in Table I.

Table I: Coordinates of the points of the contacts.

\begin{tabular}{|c|c|c|c|}
\hline Fixtures & Coordinates $(\mathrm{x}, \mathrm{y}, \mathrm{z})(\mathrm{mm})$ & Clamps & Coordinates $(\mathrm{x}, \mathrm{y}, \mathrm{z})(\mathrm{mm})$ \\
\hline L1 & $(60,20,0)$ & C1 & $(50,0,11)$ \\
\hline L2 & $(60,-20,0)$ & C2 & $(-50,0,11)$ \\
\hline L3 & $(-60,0,0)$ & C3 & $(60,-30,7)$ \\
\hline L4 & $(60,30,7)$ & C4 & $(-60,-30,7)$ \\
\hline L5 & $(-60,30,7)$ & & \\
\hline L6 & $(70,0,7)$ & & \\
\hline
\end{tabular}

We use in our simulation the same cutting conditions used in [14]. The values of the cutting conditions are presented in Table II.

Table II: Cutting conditions.

\begin{tabular}{|c|c|c|c|}
\hline Feedrate $(\mathrm{mm} / \mathrm{s})$ & Depth of cut $(\mathrm{mm})$ & Number of inserts & Spindle speed (rpm) \\
\hline 5.2 & 1 & 6 & 1000 \\
\hline
\end{tabular}


In our approach, we consider that the Hertzian model holds for all contacts. We still consider that the geometric defects of the machined surface are caused by small kinematics displacements, static and dynamic displacements of the workpiece. We suppose that the kinematic variation comes from the dimensional variations of the fixture elements, the form defects of the datum surfaces and machine tool errors. The Small static and dynamic displacements are quantified by the update (at each time step) of the surface points' coordinates of the machined surface.

In our numerical simulation, we used the same kinematic variation data used by Weiping [14]. The dimensional variation of the workpiece is considered as $\pm 0.025 \mathrm{~mm}$. Then the dimensional variation of the fixtures is considered as $\pm 0.005 \mathrm{~mm}$. The machine tool errors are presented in Table III. We neglected by assumption the geometrical errors caused by the balancing of the workpiece at the time of the action of the clamping forces. The values of the clamping forces are considered equal to $500 \mathrm{~N}$.

Table III: Machine tool data [14].

\begin{tabular}{|c|c|c|c|}
\hline Linear Accuracy & Linear Repeatability & Angular Accuracy & Angular Repeatability \\
\hline $\pm 0.005(\mathrm{~mm})$ & $\pm 0.0025(\mathrm{~mm})$ & \pm 0.0005 (Radian) & \pm 0.00005 (Radian) \\
\hline
\end{tabular}

Our simulation is based on the Monte Carlo method. Indeed we carried out a simulation on 1500 workpieces. In the first time, only the kinematical and static variations are considered in this simulation. In the second time, the machining dynamic effects are still considered. We quantified the generated geometric defects that influence the respect of the geometric condition of flatness and parallelism. Then we simulated the influence of the machining dynamic effects on the respect of the flatness and parallelism of the machined surface. We present the values of these dispersions in Table IV.

Table IV: The dispersion values of the geometric defects.

\begin{tabular}{|c|c|c|}
\hline & Without dynamic effects & With dynamic effects \\
\hline Flatness defects' dispersion $(\mathrm{mm})$ & 0.0162 & 0.0198 \\
\hline Parallelism defects' dispersion $(\mathrm{mm})$ & 0.046 & 0.058 \\
\hline
\end{tabular}

For the milling of a flexible workpiece is showed that the influence of the machining effects is considerable and especially when the dynamic behaviour of cut is critical.

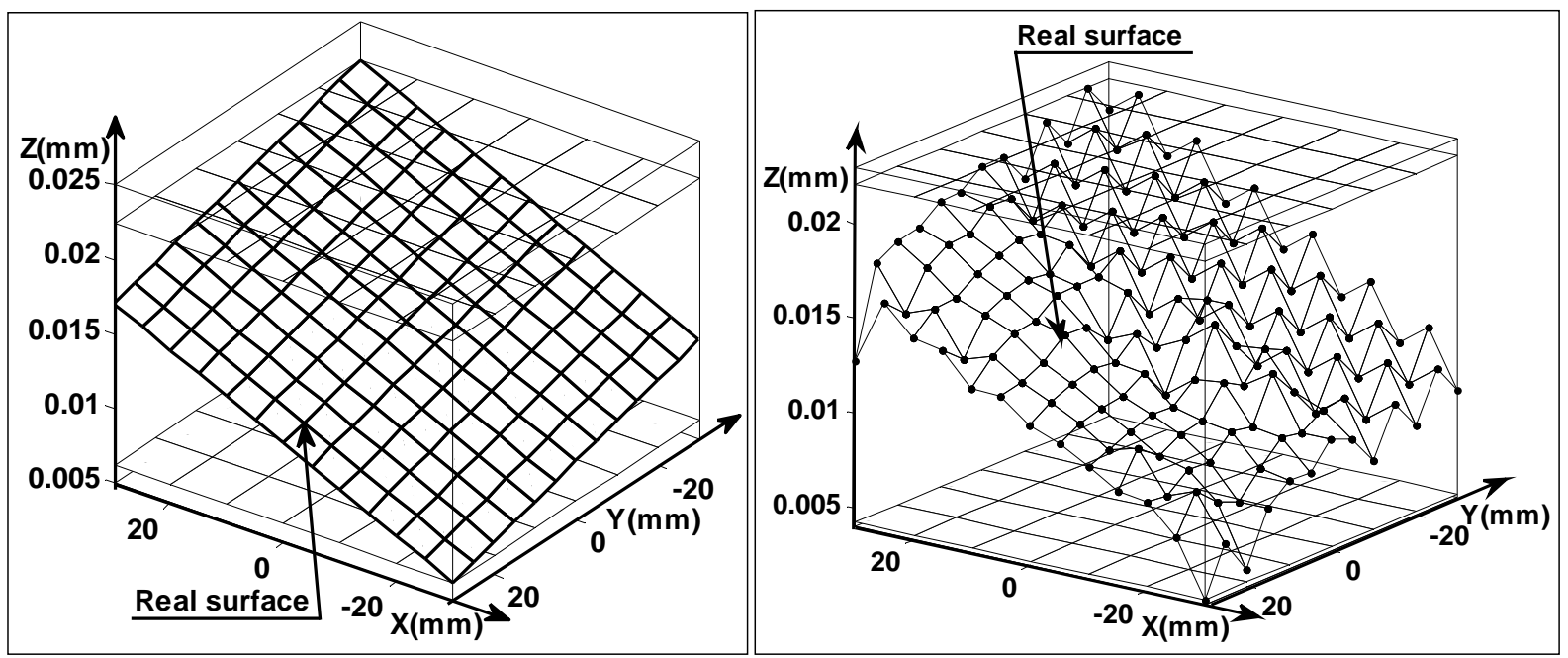

Figure 7: Influence of the geometrical defects on the flatness of the machined surface:

without presence of the dynamic effects (left), with presence of the dynamic effects (right). 
In Fig. 7 the influence of the machining dynamic effects on the flatness of the machined surface is presented.
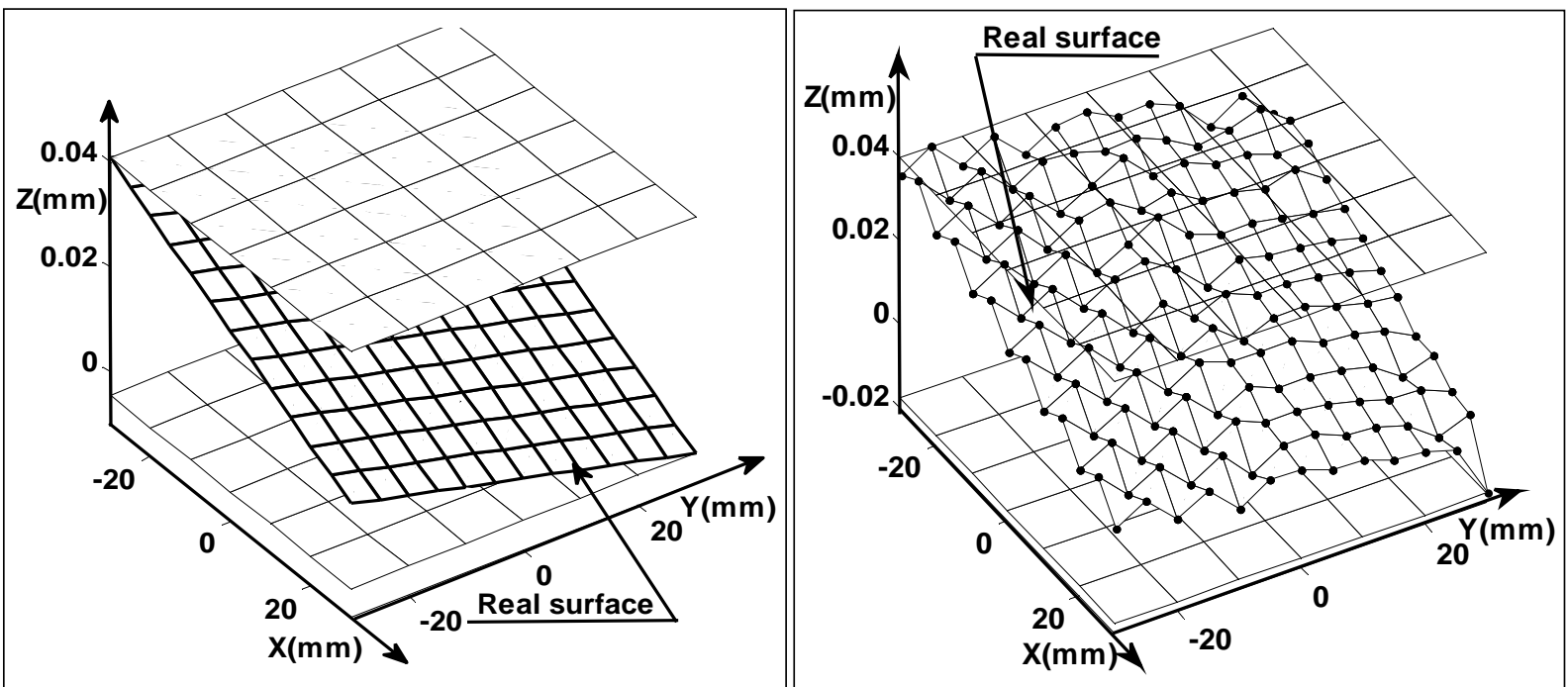

Figure 8: Influence of the geometrical defects on the parallelism of the machined surface:

without presence of the dynamic effects (left), with presence of the dynamic effects (right).

In Fig. 8 the influence of the machining dynamic defects on the parallelism of the machined surface is shown. This figure represents the orientation of the machined surface with and without the machining dynamic effects.

\section{VALIDATION OF THE RESULTS AND DISCUSSION}

We treated the same example of [13] and [14]. Then we compared the simulated results by the published results in [14]. Weiping [14] quantified the defects of flatness of two machined surfaces in two milling step. Indeed, we quantified in this simulation only the geometric defects that influence the flatness of the machined surface in the second milling step. The results published by Weiping [14] are presented in Table V.

Table V: Geometric defects that influence the flatness: published in [14].

\begin{tabular}{|c|c|c|}
\hline & Numeric results $(\mu \mathrm{m})$ & Experimental results $(\mu \mathrm{m})$ \\
\hline$\mu$ (mean) & 15.6 & 17.4 \\
\hline$\sigma$ (standard deviation) & 2.3 & 2.9 \\
\hline
\end{tabular}

The difference between the numerical and experimental results is logical. Indeed, Weiping did not take account of the machining dynamic effects in his numerical simulation. Then we can justify by our numerical results that the principal cause of this difference is the machining dynamic effects. We present in Table VI a comparison between our numerical results with the experimental results of Weiping [14] in order to validate and justify the developed model.

Table VI: Comparison between the numerical results calculated with the results of [14]

\begin{tabular}{|c|c|c|}
\hline & Numerical results simulated $(\mu \mathrm{m})$ & Experimental results [14] $(\mu \mathrm{m})$ \\
\hline Defects of flatness & 19.8 & $\mu=17.4$ and $\sigma=2.9$ \\
\hline
\end{tabular}

Through this comparative study, we could validate our model by the quantification of the flatness defects. While the validation of our model for the quantification of the defects that 
influence on the orientation and localization of the machined surface, will be a prospect for this work. Indeed, we did not find in the literature a previous research work which presents an experimentally validation for a tensorial approach quantification of geometric orientation specification.

According to Table IV, it is clearly seen that the influence of the machining dynamic effects is significant on the generation of the geometric defects and consequently on the respect of the geometrical specifications. The machining dynamic effects are more influential on the respect of the geometrical condition of flatness than the condition of parallelism. It is logical to have a more significant influence on the respect of the condition of flatness than the parallelism. Indeed in this prediction model, the thermal effects are assumed negligible while the thermal errors always exist in the experiments.

By taking account to the machining dynamic effects, we note that the geometric condition of parallelism is not respected and the geometric condition of flatness is on the limit to not be respected. We showed by this study that the machining dynamic effects affect not only surface roughness but influence the relative position between the cutting tool and workpiece and therefore affect the geometric dimensions and specifications of the newly generated surface.

\section{CONCLUSIONS}

This paper presents a methodology for modelling the geometrical machining defects by taking account of the machining dynamic effects. This methodology consists in quantifying variation sources such as kinematic error, static deformation and vibration induced error. In addition, this developed methodology evokes and evaluates the influence of the machining dynamic effects on the generation of the geometrical defects. Although this methodology is characterized by the simplicity of the mathematical formulations and a considerable profit in computing time, the deformations are considered linearly elastic and in addition the thermal error effects are not considered. The methodology is suitable in areas such as quality prediction for machining operations and engineering design for the tolerance specifications. Implementing this methodology proposed in this work would help the designer impose the tolerances more efficiently, and consequently reduce manufacturing cost and improve product quality. Indeed the results of this study will be beneficial later in future work in order to continue the simulation of the influence of the machining dynamic effects on the other geometrical specifications. In addition the future research will focus on the consideration of the influence of the errors caused by thermal error effects and the optimization of the clamping forces.

\section{REFERENCES}

[1] Shawki, G. S. A.; Abdel-Aal, M. M. (1965). Effect of fixture rigidity and wear on dimensional accuracy, International Journal of Machine Tool Design and Research, Vol. 5, No. 3, 183-202

[2] Salisbury, E. J.; Peters, F. E. (1998). The impact of surface errors on fixtured workpiece location and orientation, Trans. NAMRC/SME, Vol. 26, 323-328

[3] Chaari, R.; Louati, J.; Masmoudi, F.; Haddar, M. (2007). A tensorial modelling of the 3D influence of the fixture errors on the orientational geometric specifications, Advances in Production Engineering \& Management (APEM), Vol. 2, No. 1, 5-17

[4] De Meter, E. C. (1994). Restraint analysis of fixtures which rely on surface contact, ASME J. Eng. Ind., Vol. 116, No. 2, 207-215

[5] Hockenberger, M.; De Meter, E. C. (1995). The effect of machining fixture design parameters on workpiece displacement, Manufacturing Review, Vol. 8, No. 1, 22-32 
[6] Menassa, R. J.; DeVries, W. R. (1991). Optimization methods applied to selecting support positions in fixture design, ASME J. Eng. Ind., Vol. 113, 412-418

[7] De Meter, E. C.; Xie, W.; Choudhuri, S.; Vallapuzha, S.; Trethewey, M. W. (2001). A model to predict minimum required clamp preloads in light of fixture-workpiece compliance, International Journal of Machine Tools and Manufacture, Vol. 41, No. 7, 1031-1054

[8] Li, B.; Melkote, S. N. (2001). Optimal fixture design accounting for the effect of workpiece dynamics, International Journal of Advanced Manufacturing Technology, Vol. 18, No. 10, 701707

[9] Kaya, N.; Öztürk, F. (2003). The application of chip removal and frictional contact analysis for workpiece-fixture layout verification, International Journal of Advanced Manufacturing Technology, Vol. 21, No. 6, 411-419

[10] Liao, Y. G.; Hu, S. J. (2001). An integrated model of a fixture-workpiece system for surface quality prediction, International Journal of Advanced Manufacturing Technology, Vol. 17, No. $11,810-818$

[11] Mittal, R. O.; Cohen, P. H.; Gilmore, B. J. (1991). Dynamic modelling of the fixture-workpiece system, Robotics \& Computer-Integrated Manufacturing, Vol. 8, No. 4, 201-217

[12] Liao, Y. G.; Hu, S. J. (2000). Flexible multibody dynamics based fixture-workpiece analysis model for fixturing stability, International Journal of Machine Tools and Manufacture, Vol. 40, No. 3, 343-362

[13] Weiping, Z.; Hu, S. J. (2006). Modelling machining geometric variation in a N-2-1 fixturing scheme, Journal of manufacturing science and engineering, Vol. 128, No. 1, 213-219

[14] Weiping, Z.; Huang, Y.; Hu, S. J. (2002). Modelling variation propagation for machining systems with different configurations, Proceedings of ASME IMECE, MED, New Orleans, ASME, New York, Vol. 13, 97-106

[15] Feng, Y. (2004). A CAD based computer-aided tolerancing model for the machining process (Thesis), Computer and Information Sciences Department, Indiana University South Bend

[16] Mané, I.; Gagnol, V.; Bouzgarrou, B. C.; Ray, P. (2008). Stability-based spindle speed control during flexible workpiece high-speed milling, International Journal of Machine Tools and Manufacture, Vol. 48, No. 2, 184-194

[17] Gagnol, V.; Bouzgarrou, C. B.; Ray, P.; Barra, C. (2005). Modelling approach for a high speed machine tool spindle-bearing system, CD-ROM Proceedings of the International Design Engineering Technical Conferences, Long Beach, USA 